\title{
Affiliation of Cochlosoma to trichomonads confirmed by phylogenetic analysis of the small- subunit rRNA gene and a new family concept of the order Trichomonadida
}

Correspondence Vladimír Hampl vlada@natur.cuni.cz

\author{
Vladimír Hampl, ${ }^{1}$ Martin Vrlík, ${ }^{1}$ Ivan Cepicka, ${ }^{1}$ Zdeněk Pecka, ${ }^{2}$ \\ Jaroslav Kulda ${ }^{1}$ and Jan Tachezy ${ }^{1}$ \\ ${ }^{1}$ Department of Parasitology, Faculty of Science, Charles University, Vinicna 7, 128 44, Prague, \\ Czech Republic \\ 2Institute of Parasitology AVCR, Branišovská 31, 37005 České Budějovice, Czech Republic
}

\begin{abstract}
The protozoan genus Cochlosoma includes parasitic intestinal flagellates of birds and mammals of uncertain taxonomic classification. The presence of an adhesive disc, superficially similar to that of Giardia, led to a proposal that Cochlosoma should be classified as diplomonads. Careful morphological and ultrastructural observations, however, revealed conspicuous homologies to trichomonads. We addressed the question of classification and phylogenetic affiliation of Cochlosoma using the methods of molecular phylogenetics. Analyses based on the $16 \mathrm{~S}$ rRNA gene sequence of the species Cochlosoma anatis very robustly placed Cochlosoma in the clade of the parabasalid subfamilies Trichomonadinae, Trichomitopsiinae and Pentatrichomonoidinae of the order Trichomonadida (bootstraps >94\%). The data did not provide robust support for any particular position of Cochlosoma within this clade because the sequence suffered from mutational saturation and produced a long branch. The most probable sister taxon of Cochlosoma is the genus Pentatrichomonas, because their relationship was supported specifically by the slowest-mutating, least-saturated positions as determined using the method slow-fast. Classification of the order Trichomonadida was revised to accommodate knowledge about its phylogeny - the family Cochlosomatidae and subfamilies Trichomitopsiinae and Pentatrichomonoidinae were abandoned, Trichomonadidae was amended and new families Tritrichomonadidae (formerly a subfamily) and Trichomitidae were proposed.
\end{abstract}

\section{INTRODUCTION}

The genus Cochlosoma was established by Kotlán (1923) on the basis of the description of the type species Cochlosoma anatis from the domestic duck. This species also occurs in wild ducks and geese, coots and domestic turkeys (Kotlán, 1923) and its pathogenicity for turkey poults has been reported (Campbell, 1945; Cooper et al., 1995). Other species of Cochlosoma have been described from other birds, bats and shrews (Kulda \& Nohýnková, 1978; Pecka, 1991; Watkins et al., 1989). The most prominent structure of Cochlosoma is an adhesive disc that superficially resembles that of Giardia. This led to speculation that Cochlosoma may be related to Giardia. However, the presence of a parabasal

Published online ahead of print on 30 September 2005 as DOI 10.1099/ijs.0.63754-0.

Abbreviations: ML, maximum-likelihood; MP, maximum-parsimony.

The GenBank/EMBL/DDBJ accession number for the 16S rRNA gene sequence of Cochlosoma anatis strain AC-2 is AY247745. apparatus, pelta, costa and axostyle point to a relationship with trichomonads (Kulda \& Nohýnková, 1978). Grassé (1952) placed these parasites provisionally into the order Retortamonadida, possibly because of some morphological similarity of the lateral groove of Cochlosoma to a cytostome. A detailed ultrastructural study (Pecka et al., 1996) clearly supported the affiliation to trichomonads. Ultrastructural observations showed that, unlike Giardia, the adhesive disc of Cochlosoma is derived from the typical parabasalian structures costa and pelta. Conspicuous similarities to parabasalids were found in the Cochlosoma mastigont that includes the 'privileged kinetosomes' of parabasalids with pertinent fibrilar appendages. Of the six flagella of Cochlosoma, four are anterior and two recurrent. One recurrent flagellum is associated with a lamelliform-type of undulating membrane. Based on the ultrastructural homologies, Pecka et al. (1996) transferred the family Cochlosomatidae Tyzzer 1930 into the phylum Parabasala, order Trichomonadida. No phylogenetic study using molecular data has been performed with Cochlosoma. McElroy et al. (2005) sequenced part of the 
16S rRNA gene (466 bases) for diagnostic purposes, but did not proceed to a phylogenetic analysis. Here we present an analysis of the phylogenetic position of Cochlosoma using the major part of the $16 \mathrm{~S}$ rRNA gene.

\section{METHODS}

Organism. C. anatis strain AC-2 was isolated from a teal (Anas crecca) in České Budějovice (Czech Republic) in 1989 and subsequently maintained by serial passages in ducklings over 1 year. Intestinal scrapings, from an experimentally infected duck, resuspended in PBS ( $\mathrm{pH} 7 \cdot 4)$ were eventually cryopreserved in the presence of $5 \%(\mathrm{v} / \mathrm{v})$ DMSO and deposited in the culture collection of the Department of Parasitology, Charles University, Prague. To obtain material for DNA isolation, $200 \mu \mathrm{l}$ of the cryopreserved sample was inoculated intracloacally into a laboratory-hatched, 7day-old, protozoan-free duckling. The parasites were harvested 21 days post-inoculation from mucosal scrapings of the intestine of the euthanized duckling.

Gene amplification and sequencing. DNA was isolated from the suspension of trophozoites with the aid of a High Pure PCR Template preparation kit (Roche Diagnostics) and the $16 \mathrm{~S}$ rRNA gene was amplified using primers 16SL (5'-TACTTGGTTGATCCTGCC-3') and 16SR (5'-GTTCCATTGCCATCCACT- $3^{\prime}$ ) (Tachezy et al., 2002). The PCR mixture consisted of $1 \mathrm{mM}$ Tris/ $\mathrm{HCl}(\mathrm{pH} 9)$, $0.01 \%$ Triton X-100, $2.5 \mathrm{mM} \mathrm{MgCl}, 0.2 \mathrm{mM}$ dNTPs, $1 \mu \mathrm{M}$ of each primer, $80 \mathrm{pmol} \mathrm{DNA} \mu \mathrm{l}^{-1}$ and $0 \cdot 1 \mathrm{U}$ Taq polymerase $\mu \mathrm{l}^{-1}$. The PCR temperature profile consisted of initial denaturation at $92{ }^{\circ} \mathrm{C}$ for $4 \mathrm{~min}, 40 \mathrm{cycles}$ at $92^{\circ} \mathrm{C}$ for $30 \mathrm{~s}, 66^{\circ} \mathrm{C}$ for $30 \mathrm{~s}$ and $72{ }^{\circ} \mathrm{C}$ for $90 \mathrm{~s}$ and final polymerization at $72^{\circ} \mathrm{C}$ for $15 \mathrm{~min}$. The PCR product was purified from the gel and cloned into the vector $\mathrm{pCR}$ 2.1-TOPO using a TOPO TA cloning kit (Invitrogen). Two clones were sequenced using the vector and internal sequencing primers. Positions that differed in the sequences of the clones were determined by direct sequencing from the PCR products.

Tree construction. Alignments were constructed using the CLUSTAL_X program (Thompson et al., 1997) and manually refined using BioEdit (Hall, 1999). The eukaryotic analysis (1006 positions after editing) included Cochlosoma, 8 parabasalian and 33 other eukaryotic sequences, the broader parabasalian analysis (1175 positions after editing) included Cochlosoma and 77 parabasalian sequences, and the narrower analysis (1552 positions after editing) included Cochlosoma, 12 Trichomonadinae, 2 Trichomitopsiinae, 1 Pentatrichomonoidinae and 4 outgroup sequences. The number of positions in the narrower analysis was reduced in the course of slow-fast analysis (see below). All alignments are available upon request (vlada@natur.cuni.cz).

Phylogenetic trees were constructed using the maximum-likelihood (ML) method in PHYML (Guindon \& Gascuel, 2003) $(\mathrm{TrN}+\mathrm{I}+\Gamma$ or GTR $+\mathrm{I}+\Gamma$ as recommended by MODELTEST 3.06, parameters optimized by the software, 100 bootstrap replicates in the eukaryotic and the broad parabasalian analyses and 1000 in the narrow parabasalian analysis), the Bayesian method in MrBayes 3.0 (Ronquist \& Huelsenbeck, 2003) (lset nst $=6$ rates $=$ invgamma covarion $=y e s$, temp 0·2, 4 simultaneous MCMC chains, 2000000 generations; trees from generations before the chain reached equilibrium were removed as the 'burn-in'), the maximum-parsimony (MP) method in PAUP 4.0 (Swofford, 1998) (hsearch start $=$ stepwise addseq $=$ random nrep $=10$, 1000 bootstrap replicates) and the neighbour-joining method in PAUP 4.0 (LogDet distances, 1000 bootstrap replicates).

Slow-fast analysis. The slow-fast method (Brinkmann \& Philippe, 1999) was used to estimate and to lower the effect of longbranch attraction artefact by sequential removal of positions with high mutational rates that are supposedly responsible for stochastic information noise. In this method, the positions in the alignment were divided into four classes according to their increasing mutational rate. The mutational rate class corresponded to the total number of changes that occurred at the position within the five wellsupported clades with robust internal topology: (i) Trichomonas tenax and Trichomonas vaginalis; (ii) Pseudotrichomonas keilini, Monocercomonas ruminantium, Monotrichomonas carabina and Ditrichomonas honigbergii; (iii) Trichomitopsis termopsidis, Pseudotrypanosoma giganteum and Reticulitermes speratus symbiont; (iv) Tetratrichomonas limacis, Tetratrichomonas prowazeki, Tetratrichomonas gallinarum strain A6, Tetratrichomonas gallinarum strain GPO and Kalotermes flavicollis symbiont; and (v) Trichomonoides trypanoides and Hodotermopsis sjoestedti symbiont. The number of changes was estimated in PAUP 4.0 using the 'describetrees' command in MP mode. New alignments $(\mathrm{s} 0, \mathrm{~s} 1, \mathrm{~s} 2)$ were created from the original alignment by exclusion of positions with more than zero, one and two changes, respectively. Phylogenetic trees were constructed from these alignments. Average bootstrap values and average posterior probabilities were calculated from the node values in each tree to monitor the change in overall tree robustness. Because the slow-fast method is based on the gradual exclusion of positions carrying information on the internal topology of the above-mentioned five clades, and hence the bootstraps of these nodes decrease as the sequences become identical at the s0 level, these nodes were not included in the calculation of average bootstrap values and average posterior probabilities.

The saturation analysis was performed using the program package MUST (Philippe, 1993).

\section{RESULTS}

The sequenced part of the $16 \mathrm{~S}$ rRNA gene of $C$. anatis was 1508 bp long. In the phylogenetic tree (Fig. 1), which was rooted using 30 representatives of various eukaryotic groups, the sequence formed a clade with other parabasalids and the clade received the maximum statistical support. In the parabasalian phylogenetic tree (Fig. 2), the C. anatis sequence robustly branched in the clade of Trichomonadinae, Trichomitopsiinae and Pentatrichomonoidinae (bootstrap values $94-96 \%)$.

For a detailed analysis of the position of $C$. anatis within this clade, a new alignment was created comprising only C. anatis, representatives of the clade and four outgroups (Pseudotrichomonas keilini, Monocercomonas ruminantium, Monotrichomonas carabina and Ditrichomonas honigbergii). In the tree constructed from this alignment (Fig. 3a), Cochlosoma branched with moderate support as a sister taxon to Pentatrichomonoides scroa. The sequence of Cochlosoma produced a relatively long branch, indicating an accelerated mutational rate. Deciphering the phylogenetic relationship of such a sequence is complicated by the fact that certain positions in the sequence might be substitutionally saturated, as they may have undergone more than one substitution, and the information carried by these positions is thus confusing. Consequently, the statistical support for placement of such a sequence in the tree decreases and the sequence may even be misplaced due to artificial attraction to other saturated or highly divergent sequences (Felsenstein, 1978).

One way of assessing the degree of saturation in a dataset is to plot for each pair of taxa the number of observed differences 


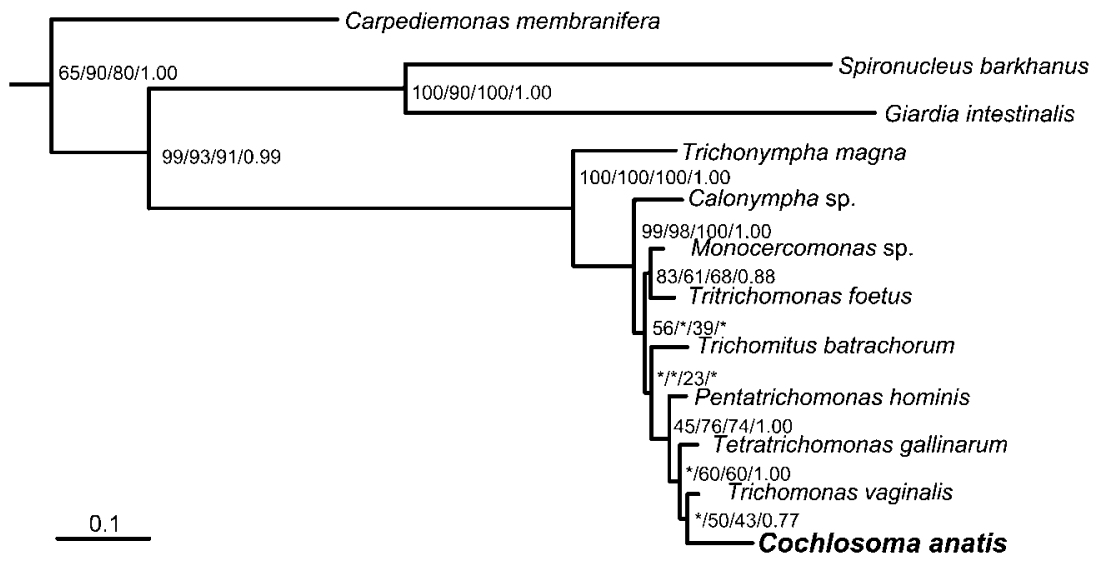

Fig. 1. Rooted phylogenetic tree of Parabasala and related taxa based on 16S rRNA gene sequences. The tree was constructed by using the ML method in PHYML with the GTR $+\mathrm{I}+\Gamma$ model of substitution. Numbers at nodes indicate statistical support estimated by four methods (distance bootstrap/MP bootstrap/ML bootstrap/ MrBayes posterior probability; asterisks indicate that the node was not recovered using that method). To save space, the 30 eukaryotic outgroups are not shown; their position is indicated by the left-most horizontal line. Bar, 10\% substitutions.

against the estimate of the 'true' number of substitutions. Such a plot for all ingroup pairs of taxa from the narrow dataset is shown in Fig. 3(c). The 'true' number of substitutions was estimated from the ML tree constructed in PHYML. If no saturation was present, the number of observed differences would be equal to the number of inferred substitutions (dashed line). In the case of our dataset, the number of observed differences was lower and the difference increased in more distant taxa, indicating that saturation was present. As expected, the highest degree of saturation was detected in pairs including Cochlosoma (open circles).

The influence of substitutional saturation on the topology reconstruction can be reduced by using the slow-fast method. The essence of this method involves estimation of the mutational rate of each position, then step-by-step exclusion of the fastest, and potentially most saturated, positions from the alignment and monitoring how this affects the resulting topology. The positions in our alignment were divided into four classes (0-3) of increasing mutational rate (see Methods). New alignments s2, s1 and s0 were created, from which the positions of rate class $3,2+3$ and $1+2+3$, respectively, were excluded. In all trees constructed from alignments s2 and s1, Cochlosoma branched with low statistical support as a sister taxon to Pentatrichomonoides scroa, as in the original tree. Conversely, in the trees constructed from the s0 alignment, Cochlosoma branched as a sister taxon to Pentatrichomonas hominis, although the bootstrap support was still low $(52-56 \%)$. As expected, the saturation plot of the s0 alignment (Fig. 3d) showed a considerably lower degree of saturation. Because the presence of the long branch leading to outgroups might enhance the long-branch attraction artefact, all analyses were repeated without the outgroups. The results of these analyses were almost identical. The trees constructed from alignments s1 and greater supported the relationship of Cochlosoma and Pentatrichomonoides, whereas in the trees based on the s0 alignment, Cochlosoma branched with Pentatrichomonas, this time with moderate $(65-77 \%)$ bootstrap support. The change in statistical support for Cochlosoma-Pentatrichomonoides and Cochlosoma-Pentatrichomonas nodes and the change in overall support of the tree in each step of the fast-sites exclusion are depicted graphically in Fig. 4. The overall tree robustness, counted as the average of bootstrap values or of posterior probabilities of the tree nodes, changed only slightly (dashed lines). The support of the CochlosomaPentatrichomonas node gradually increased with fast-sites exclusion in all tree construction methods (solid lines). The most prominent increase took place between the $s 1$ and $s 0$ alignments and was accompanied by a sudden decrease in the support for the Cochlosoma-Pentatrichomonoides node (dotted lines).

\section{DISCUSSION}

Phylogenetic analysis based on the 16S rRNA gene sequence of $C$. anatis undoubtedly showed that this protist belongs in the phylum Parabasala. The relationships within Parabasala recovered in our analyses correspond mainly to previously published results (e.g. Keeling, 2002; Gerbod et al., 2002; Hampl et al., 2004; Ohkuma et al., 2005). The observed differences in the shape of deeper nodes can be ascribed to the long-branch attraction or to stochastic forces, as the statistical support for many nodes in all analyses was rather low. The Cochlosoma sequence was robustly placed in the clade consisting of representatives of the subfamilies Trichomonadinae, Trichomitopsiinae and Pentatrichomonoidinae. The classification of Cochlosoma in Parabasala has already been suggested in the ultrastructural study by Pecka et al. (1996) that demonstrated the presence of several parabasalid characters in this protozoan (costa, parabasal body and fibres, axostyle, hydrogenosome-like bodies). The affiliation of Cochlosoma specifically to the subfamily Trichomonadinae is also morphologically reasonable, as the major morphological characters of members of Trichomonadinae (B-type costa and the lamelliform-type of undulating membrane) are present in Cochlosoma.

The 16S rRNA gene phylogeny did not explicitly determine the position of Cochlosoma among genera within the 


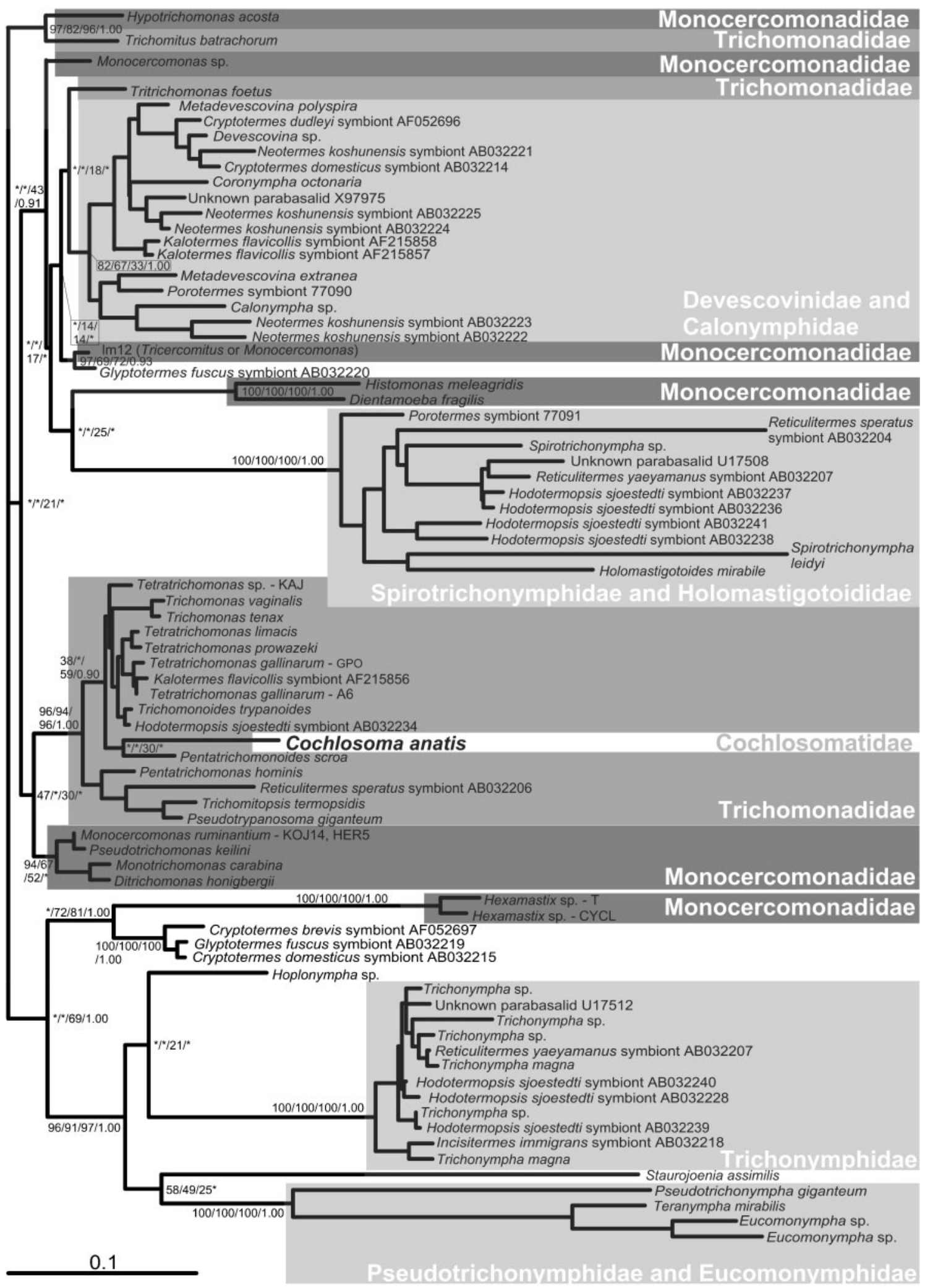

Fig. 2. Unrooted phylogenetic tree of Parabasala based on $16 \mathrm{~S}$ rRNA gene sequences. The tree was constructed by using the $\mathrm{ML}$ method in PHYML with the $\mathrm{TrN}+\mathrm{I}+\Gamma$ model of substitution. Numbers at nodes indicate statistical support estimated by four methods (distance bootstrap/MP bootstrap/ML bootstrap/MrBayes posterior probability; asterisks indicate that the node was not recovered using that method). GenBank accession numbers are given for the termite-symbiont sequences. Bar, $10 \%$ substitutions. 
Complete alignment - 1552 positions

(a)

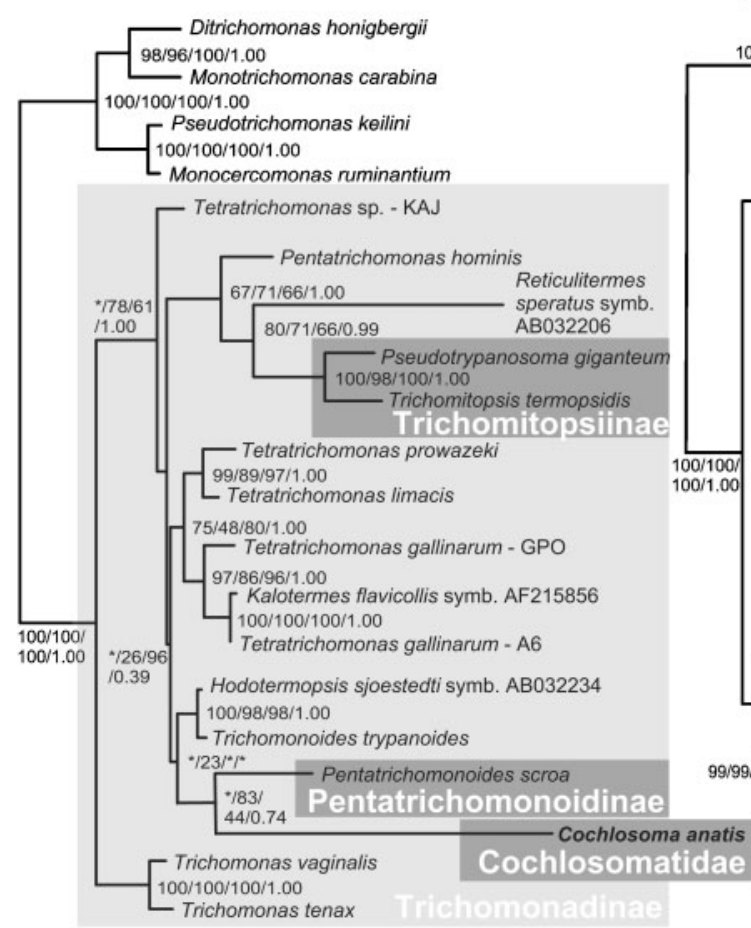

0.1

(c)

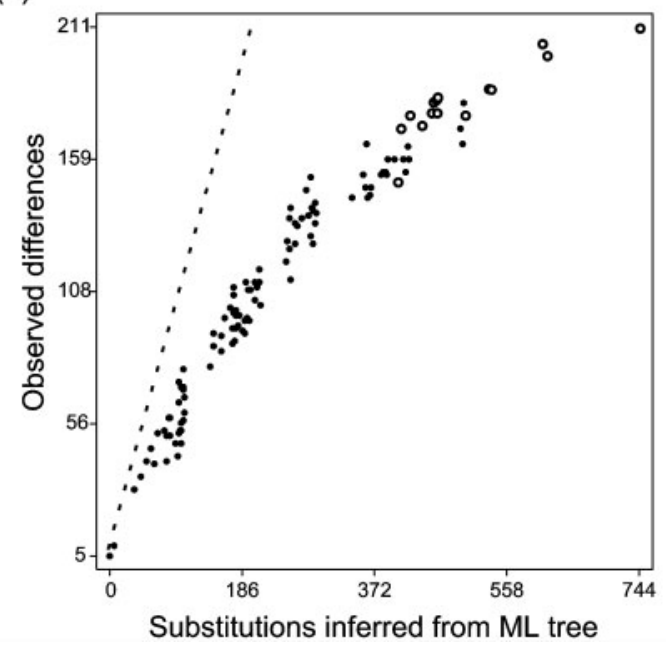

s0 alignment - 1224 positions

(b)

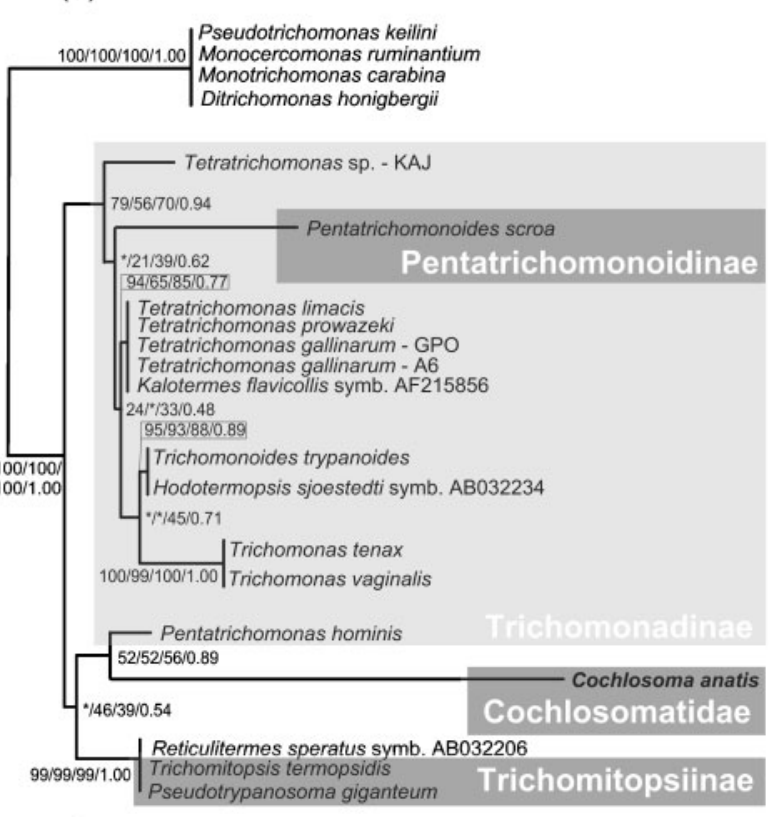

$\underline{0.01}$

(d)

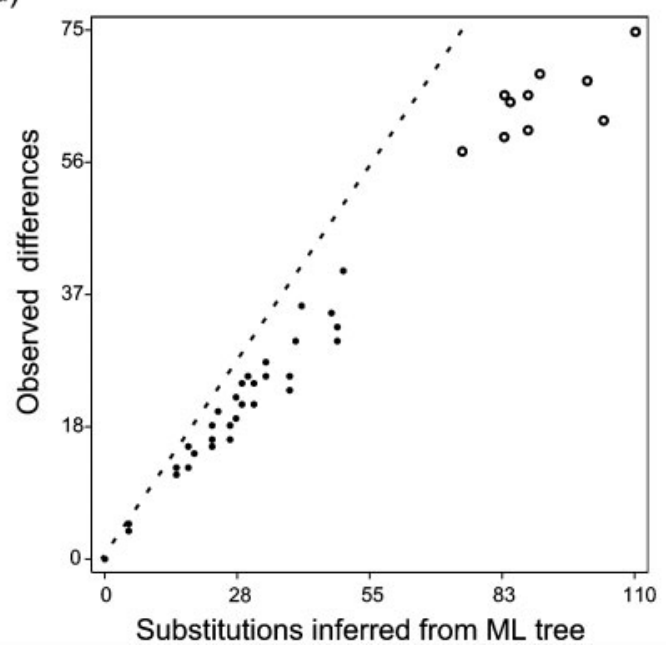

Fig. 3. Phylogenetic trees and saturation plots for the $16 \mathrm{~S}$ rRNA gene sequences of Cochlosoma, Trichomonadinae, Trichomitopsiinae and Pentatrichomonoidinae. (a) Phylogenetic tree - complete alignment. The tree was constructed by using the ML method in PHYML with the TrN $+\mathrm{I}+\Gamma$ model of substitution. Numbers at nodes indicate statistical support estimated by four methods (distance bootstrap/MP bootstrap/ML bootstrap/MrBayes posterior probability; asterisks indicate that the node was not recovered using that method). The tree was rooted with sequences of Pseudotrichomonas keilini, Monocercomonas ruminantium, Monotrichomonas carabina and Ditrichomonas honigbergii. GenBank accession numbers are given for the termite-symbiont sequences. Bar, 10\% substitutions. (b) Phylogenetic tree - alignment so. Details as for (a). Bar, 1\% substitutions. (c) Saturation plot - complete alignment. For each pair of taxa, the number of observed differences is plotted against the number of substitutions inferred from the ML tree. The dashed line represents the ideal case where the numbers of observed differences and inferred substitutions are equal. The pairs of taxa including Cochlosoma are marked by open circles. (d) Saturation plot - alignment s0. Details as for (c). 


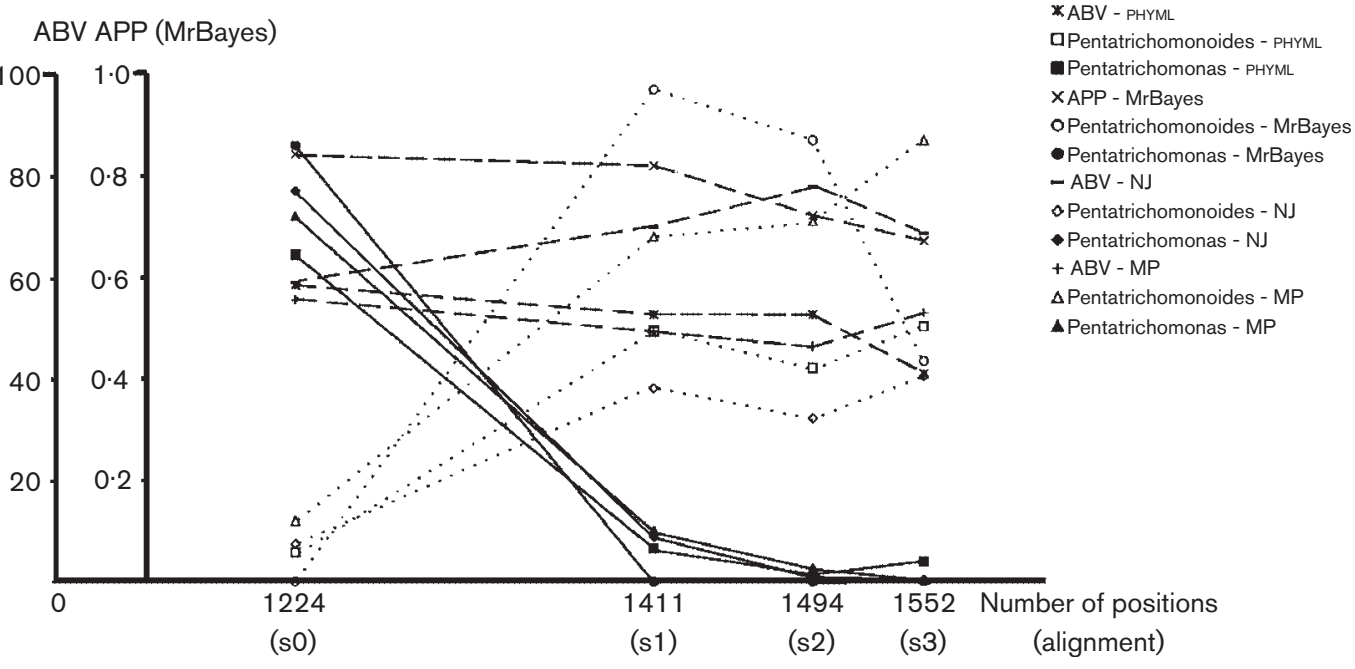

Fig. 4. Result of the slow-fast analysis of Cochlosoma, Trichomonadinae, Trichomitopsiinae and Pentatrichomonoidinae datasets without outgroups. Diagram of changes in overall tree robustness (dashed lines) and in statistical support for the common branch of Cochlosoma with Pentatrichomonoides (dotted lines) and Cochlosoma with Pentatrichomonas (solid lines) determined using various tree construction methods. The overall tree robustness is expressed as the average posterior probability (APP) of tree nodes computed by the Bayesian method in MrBayes 3.0 and in average bootstrap values (ABV) of tree nodes computed by MP and distance methods [neighbour-joining (NJ)] in PAUP4.0 and ML method in PHYML.

aforementioned clade. At the root of this problem lies the increased mutational rate of the Cochlosoma sequence, manifested in the long branch of Cochlosoma. The fast mutational rate wiped off part of the phylogenetic information, because a fraction of sites in the sequence became mutationally saturated. The phylogenetic reconstruction based on all 1552 aligned sites placed Cochlosoma as a sister to the genus Pentatrichomonoides. The support for the common branch of Cochlosoma and Pentatrichomonoides, however, decreased after exclusion of the fast and supposedly most saturated sites. Simultaneously, the support for the relationship between Cochlosoma and the genus Pentatrichomonas increased. Although the changes were only minor after exclusion of the 141 fastest positions, they became very sharp after exclusion of another 187 fast positions. After exclusion of these positions, the mutational saturation in the dataset was reduced considerably. The support for the Cochlosoma-Pentatrichomonas relationship further increased when the outgroup sequences were excluded from the analysis.

As the relationship between Cochlosoma and Pentatrichomonas was supported by the slowest and least-saturated positions, it is more reliable than the relationship with Pentatrichomonoides, which could result from the longbranch attraction. Moreover, certain similarities can also be found in the ultrastructure of Cochlosoma and Pentatrichomonas. In species of both genera, the kinetosome of the sixth flagellum is situated outside the complex of the other kinetosomes, and lies perpendicular to those of the anterior flagella, thus representing the second recurrent flagellum (Honigberg et al., 1968; Brugerolle, 1976; Pecka et al., 1996).
In Pentatrichomonoides, the sixth flagellum is anterior, with its kinetosome located within the kinetosomal complex in parallel with those of the other anterior flagella (Brugerolle et al., 1994). There is, however, a developmental difference between the mastigonts of Pentatrichomonas and Cochlosoma. The interphase form of Pentatrichomonas possesses five flagella (four anterior, one recurrent). The specimens with the sixth flagellum, although pervasive in the population, apparently represent the early stage of cytokinesis, their sixth flagellum representing a precursor of a new recurrent flagellum of the daughter cell. This is not the case with Cochlosoma, where the sixth flagellum appears to be a permanent feature of the non-dividing cell (Pecka et al., 1996). The ultrastructural study of Pecka et al. (1996) revealed a unique structure in Cochlosoma, ribbons composed of tiny tubules ( $8 \mathrm{~nm}$ in diameter) attached to the microtubules of the pelta that, in Cochlosoma, forms the basis of the adhesive disc cytoskeleton. Although not reported previously in other flagellates, a structure such as this was found later in Pseudotrypanosoma (Brugerolle, 1999). Pseudotrypanosoma and Cochlosoma were both placed in the same part of the tree. However, our analysis undoubtedly rejected the possibility of the two taxa being exclusive sister branches; the closest relative of Pseudotrypanosoma was the genus Trichomitopsis with $100 \%$ bootstrap support. The most probable explanation for the presence of these unique tubules in Cochlosoma and Pseudotrypanosoma might be secondary loss in the genera Pentatrichomonas and Trichomitopsis.

The classification of Cochlosoma in the separate family Cochlosomatidae (Pecka et al., 1996) conflicts with the 
phylogenetic affiliations of Cochlosoma revealed in our analysis, because Cochlosoma was placed in the robust clade comprising exclusively representatives of the family Trichomonadidae. However, the easiest solution, reclassification of Cochlosomatidae as a subfamily of Trichomonadidae, is problematic. The tree shown in Fig. 3(b) represents the most reliable tree of the clade, because it is based on slow-mutating positions and is in agreement with results of other analyses (Keeling, 2002; Gerbod et al., 2002; Hampl et al., 2004; Ohkuma et al., 2005). If we consider the tree to be correct, establishing the subfamily Cochlosomatinae and keeping the recognized subfamilies Trichomitopsiinae Brugerolle 1977 (Trichomitopsis, Pseudotrypanosoma) and Pentatrichomonoidinae Honigberg 1963 (Pentatrichomonoides) would inevitably mean that Trichomonadinae must be divided into two or even three subfamilies: (i) Pentatrichomonas; (ii) possibly Tetratrichomonas strain KAJ; and (iii) the remaining taxa. Such overcomplicated subdividing of the relatively small group of organisms into three subtaxa, which would not be easy to define morphologically, in our opinion would be inappropriate; moreover, some relationships in the tree are too poorly supported to serve as a base for revision. Another and our preferred approach as to how to harmonize the classification with the tree would be to join all taxa in the clade Cochlosomatidae, Trichomitopsiinae, Pentatrichomonoidinae and the genera Trichomonas, Trichomonoides, Tetratrichomonas and Pentatrichomonas - into the single amended family Trichomonadidae. The family can be well defined by the B-type of costa, the lamelliform undulating membrane and by the absence of both a comb-like structure and infrakinetosomal body in the mastigont. Remaining taxa of the former Trichomonadidae, i.e. the genera Trichomitus (formerly part of the subfamily Trichomonadinae) and Tritrichomonas (formerly the subfamily Tritrichomonadinae), are not monophyletic with the amended Trichomonadidae. We propose that the genera Trichomitus and Tritrichomonas should form the independent families Trichomitidae and Tritrichomonadidae. The family Trichomitidae, which includes a single genus, Trichomitus, is characterized by the A-type of costa, by a lamelliform undulating membrane and by the presence of a comb-like structure in the mastigont. The family Tritrichomonadidae, which includes the single genus Tritrichomonas, is characterized by the A-type of costa, by a rail-type undulating membrane and by the presence of both a comblike structure and infrakinetosomal body in the mastigont.

Our new classification is closer to the natural system because it reorganizes the highly polyphyletic former Trichomonadidae together with Cochlosomatidae into three morphologically well-defined monophyla. This revision, however, does not solve all the problems of parabasalian systematics, because other higher taxa are still non-monophyletic, namely the family Monocercomonadidae and order Trichomonadida. Solving these issues is beyond the scope of the present paper and can only be achieved together with a general revision of the phylum Parabasala. It is to be expected that some taxa in the future will be incorporated into the newly established families or vice versa, e.g. the genus Hypotrichomonas to Trichomitidae, free-living genera and the genera Hexamastix and Tricercomitus to Trichomonadidae and Tritrichomonadidae to Cristamonadida.

\section{Taxonomic summary}

\section{Trichomonadida Kirby 1947}

Diagnosis: parabasalids with a single karyomastigont, one to five anterior flagella or flagellar system absent, costa present or absent, cresta absent.

\section{Monocercomonadidae Kirby 1944}

Diagnosis: one to five anterior flagella or flagellar system absent, undulating membrane present or absent, costa absent, comb-like structure and infrakinetosomal body in mastigont present or absent, parabasal body of various shapes.

Type genus Monocercomonas Grassi 1879.

\section{Trichomonadidae Chalmers \& Pekkola 1918 emend.}

Diagnosis: four or five anterior flagella, undulating membrane of lamelliform-type, costa of B-type present, neither comb-like structure nor infrakinetosomal body present in mastigont, parabasal body of various shapes.

Type genus Trichomonas Donné 1836.

Other genera: Tetratrichomonas Parisi 1910; Pentatrichomonas Mesnil 1914; Pseudotrypanosoma Grassi 1917; Trichomitopsis Kofoid \& Swezy 1919; Cochlosoma Kotlán 1923; Pentatrichomonoides Kirby 1931; Trichomonoides Brugerolle \& Bordereau 2004.

\section{Tritrichomonadidae Honigberg 1963 emend.}

Diagnosis: three or four anterior flagella, undulating membrane of rail-type, costa of A-type present, comb-like structure and infrakinetosomal body present in mastigont, parabasal body rod-shaped. Previously held the rank of subfamily.

Type genus Tritrichomonas Kofoid 1920.

No other genera.

\section{Trichomitidae fam. nov.}

Diagnosis: three anterior flagella, undulating membrane of lamelliform-type, costa of A-type present, comb-like structure, but not infrakinetosomal body, present in mastigont. Parabasal body biramous.

Type genus Trichomitus Swezy 1915.

No other genera. 


\section{ACKNOWLEDGEMENTS}

The authors thank Dr Pecková for providing the strain of C. anatis. This work was supported by grant GAUK 264/1999 and MŠMT project 0021620828 .

\section{REFERENCES}

Brinkmann, H. \& Philippe, H. (1999). Archaea sister group of bacteria? Indications from tree reconstruction artifacts in ancient phylogenies. Mol Biol Evol 16, 817-825.

Brugerolle, G. (1976). Cytologie ultrastructurale, systematique et evolution des Trichomonadida. Ann Stn Biol Besse-en-Chandesse 10, 1-57 (in French).

Brugerolle, G. (1999). Fine structure of Pseudotrypanosoma giganteum of porotermes, a trichomonad with a contractile costa. Eur J Protistol 35, 121-128.

Brugerolle, G., Breunig, A. \& König, H. (1994). Ultrastructural study of Pentatrichomonoides sp., a trichomonad flagellate from Mastotermes darwiniensis. Eur J Protistol 30, 372-378.

Campbell, J. G. (1945). An infection of young turkeys associated with Cochlosoma sp. Vet J 101, 255-259.

Cooper, G. L., Shivaprasad, H. L., Bickford, A. A., Nordhausen, R., Munn, R. J. \& Jeffrey, J. S. (1995). Enteritis in turkeys associated with an unusual flagellated protozoan (Cochlosoma anatis). Avian Dis 39, 183-190.

Felsenstein, J. (1978). Cases in which parsimony or compatibility methods will be positively misleading. Syst Zool 27, 401-410.

Gerbod, D., Noël, C., Dolan, M. F. \& 9 other authors (2002). Molecular phylogeny of parabasalids inferred from small subunit rRNA sequences, with emphasis on the Devescovinidae and Calonymphidae (Trichomonadea). Mol Phylogenet Evol 25, 545-556.

Grassé, P. P. (1952). Traité de Zoologie. Tome I - Phylogénie Protozoaires: Géneralités Flagellés. Paris: Masson et Cie (in French).

Guindon, S. \& Gascuel, O. (2003). A simple, fast and accurate algorithm to estimate large phylogenies by maximum likelihood. Syst Biol 52, 696-704.

Hall, T. A. (1999). BioEdit: a user-friendly biological sequence alignment editor and analysis program for Windows 95/98/NT. Nucleic Acids Symp Ser 41, 95-98.

Hampl, V., Cepicka, I., Flegr, J., Tachezy, J. \& Kulda, J. (2004). Critical analysis of the topology and rooting of the parabasalian $16 \mathrm{~S}$ rRNA tree. Mol Phylogenet Evol 32, 711-723.
Honigberg, B. M., Mattern, C. F. \& Daniel, W. A. (1968). Structure of Pentatrichomonas hominis (Davaine) as revealed by electron microscopy. J Protozool 15, 419-430.

Keeling, P. J. (2002). Molecular phylogenetic position of Trichomitopsis termopsidis (Parabasalia) and evidence for the Trichomitopsiinae. Eur J Protistol 38, 279-286.

Kotlán, A. (1923). Zur Kenntnis der Darmflagellaten aus der Hausente und anderen Wasservögeln. Zentralbl Bakteriol Parasitenkd Infektionskr Hyg 90, 24-28 (in German).

Kulda, J. \& Nohýnková, E. (1978). Flagellates of the human intestine and of intestines of other species. In Parasitic Protozoa, pp. 1-138. Edited by J. P. Kreier. New York: Academic Press.

McElroy, S. M., Szalanski, A. L., McKay, T., Bermudez, A. J., Owens, C. B. \& Steelman, C. D. (2005). Molecular assay for the detection of Cochlosoma anatis in house flies and turkey specimens by polymerase chain reaction. Vet Parasitol 127, 165-168.

Ohkuma, M., lida, T., Ohtoko, K., Yuzawa, H., Noda, S., Viscogliosi, E. \& Kudo, T. (2005). Molecular phylogeny of parabasalids inferred from small subunit rRNA sequences, with emphasis on the Hypermastigea. Mol Phylogenet Evol 35, 646-655.

Pecka, Z. (1991). Domestic geese (Anser anser L.) as a new host of Cochlosoma anatis Kotlán, 1923. Folia Parasitol 38, 91-92.

Pecka, Z., Nohýnková, E. \& Kulda, J. (1996). Ultrastructure of Cochlosoma anatis Kotlán, 1923 and taxonomic position of the family Cochlosomatidae (Parabasala: Trichomonadida). Eur $J$ Protistol 32, 190-201.

Philippe, H. (1993). MUST, a computer package of management utilities for sequences and trees. Nucleic Acids Res 21, 5264-5272.

Ronquist, F. \& Huelsenbeck, J. P. (2003). MrBayes 3: Bayesian phylogenetic inference under mixed models. Bioinformatics 19, 1572-1574.

Swofford, D. L. (1998). PAUP*: Phylogenetic Analysis Using Parsimony (*and other methods), version 4. Sunderland, MA: Sinauer Associates.

Tachezy, J., Tachezy, R., Hampl, V., Šedinová, M., Vaňáčová, Š., Vrlik, M., Van Ranst, M., Flegr, J. \& Kulda, J. (2002). Cattle pathogen Tritrichomonas foetus (Riedmuller, 1928) and pig commensal Tritrichomonas suis (Gruby \& Delafond, 1843) belong to the same species. J Eukaryot Microbiol 49, 154-163.

Thompson, J. D., Gibson, T. J., Plewniak, F., Jeanmougin, F. \& Higgins, D. G. (1997). The CLUSTAL_X windows interface: flexible strategies for multiple sequence alignment aided by quality analysis tools. Nucleic Acids Res 25, 4876-4882.

Watkins, R. A., O'Dell, W. D. \& Pinter, A. J. (1989). Redescription of flagellar arrangement in the duck intestinal flagellate, Cochlosoma anatis and description of a new species, Cochlosoma soricis n. sp. from shrews. J Protozool 36, 527-531. 